\title{
Colonization of Intestinal Bacteria in the Normal Neonate: Comparison Between Mouth and Rectal Swabs and Small and Large Bowel Specimens
}

\author{
By Joan M. Van Camp, Robert Drongowski, Robert Gorman, Maher Altabba, \\ Ronald B. Hirschl, and Arnold G. Coran \\ Ann Arbor, Michigan
}

\begin{abstract}
- Seventy-four New Zealand white rabbit pups were divided into four groups: group I, 2 days of age $(n=9)$; group II, 3 to 5 days of age $(n=24)$; group III, 6 to 8 days of age $(n=27)$; and group IV, 10 to 13 days of age $(n=14)$. Mouth swabs (MS), rectal swabs (RS), small bowel specimens [SB], and large bowel specimens (LB) were obtained from each rabbit, incubated for $\mathbf{2 4}$ hours in thioglycolate broth, and plated on blood agar in aerobic and anaerobic environments. After 24 hours, growth on blood agar plates were observed. All MS specimens and all but one RS specimen showed positive growth. Growth of both LB and SB specimens increased significantly with age $(P<.04)$. In addition, SB growth was significantly less than RS or MS growth in groups I, II, and III $(P<, 05)$. LB growth was significantly less than RS or MS growth in group I $(P<.01)$ and tended to be less in groups II and III $162.5 \%$ v $100 \%$ and $93 \% \vee 100 \%$, respectively). These data show that nearly half of normal rabbits under 6 days of age have sterile small and large intestines despite almost $100 \%$ growth from rectal and mouth swabs. These findings partially explain the absence of spontaneous bacterial translocation in young rabbit pups (under 4 days of age) and have important implications for the prophylaxis and treatment of neonatal sepsis. Copyright 11994 by W.B. Saunders Company
\end{abstract}

INDEX WORDS: Intestinal colonization, neonate; bacterial translocation.

$\mathbf{P}$ REVIOUS STUDIES in our laboratory on bacterial translocation have shown that normal neonatal rabbits (4 to 6 days of age) translocate significantly more than do older rabbits (more than 12 days of age) ${ }^{1}$; however, very young rabbits (under 4 days of age) did not translocate. Further analysis of our results showed that many large and small bowel specimens from rabbits under 1 week of age were sterile. Because bacteria must be present in the bowel for bacterial translocation to occur, the sterility of the bowel specimens explained the lack of bacterial translocation in the young neonates. This observation prompted several questions regarding the exact timing of intestinal colonization in the neonate.

From the Section of Pediatric Surgery, C.S. Mott Children's Hospital, the University of Michigan Medical Center, and the University of Michigan Medical School, Ann Arbor, MI

Date accepted: August 25, 1993.

Address reprint requests to Amold $G$. Coran, $M D$, Section of

Pediatric Surgery, L2110 MCHC, Box 0245, Ann Arbor, MI 48109.

Copyright $\odot 1994$ by W.B. Saunders Company

0022-3468/94/2910-0014\$03.00/0
Little is known about the exact timing of bacterial colonization of the normal neonatal bowel. Although several articles have been written about the various types of bacteria that colonize in the intestines of infants who are breast-fed, bottle-fed, in the intensive care unit, delivered vaginally, or delivered by cesarean section, ${ }^{2-6}$ all the studies used either rectal swabs (RS) or fecal specimens to isolate and identify bacterial colonization. These studies have shown that bacterial growth occurs in the rectum or feces of nearly all neonates within 2 days of birth. Despite the fact that actual colon and small bowel (SB) specimens were not evaluated, these studies have led to the general belief that the intestines are colonized within 48 hours after birth.

In contrast, our observations suggest that neonatal intestinal colonization occurs later than is generally believed and that growth from RS or fecal specimens is not reflective of actual intestinal colonization. Knowledge of the timing of neonatal bowel colonization will have a profound impact on the prevention and treatment of diseases of the neonate such as necrotizing enterocolitis and on bacterial translocation, which may progress to sepsis, multiple-system organ failure, and death.

\section{MATERIALS AND METHODS}

Seventy-four New Zealand White rabbit pups were divided into four groups based on age. Group I rabbits were 2 days old $(\mathrm{n}=9)$; group II were 3 to 5 days old ( $\mathrm{n}=24)$; group III were 6 to 8 days old $(n=27)$; and group IV were 10 to 13 days old $(n=14)$. Each group was raised in the rabbitory and allowed to feed ad libitum from their mother until the time of delivery to the University of Michigan's Unit for Laboratory Medicine (ULAM). All rabbits were killed within 24 hours of delivery to ULAM and did not receive any feeding while at ULAM.

The rabbits were sedated with acepromazine $(1 \mathrm{mg} / \mathrm{kg}$ subcutaneously) and ketamine ( $50 \mathrm{mg} / \mathrm{kg}$ intramuscularly). After sedation, the rabbits were placed supine on the operating table. Rectal and mouth swabs (MS) were obtained by carefully inserting two sterile cotton-tipped applicators into the anal canal and oral cavity, respectively. The swabs were placed into sterile tubes containing 3 $\mathrm{mL}$ of thioglycolate broth. This broth allows for growth of both aerobic and anaerobic bacteria.

After obtaining rectal and mouth swabs, the anterior abdominal wall was prepared with betadine and stcrilely draped. A midline abdominal incision was made from the xyphoid to the pubis. Using new gloves and sterile instruments, representative sections of mid small and large bowel (LB) (approximately 0.5 to $1.0 \mathrm{~cm}$ in length) 
were excised. The bowel sections were placed into sterile tubes containing $3 \mathrm{~mL}$ of thioglycolate broth.

All the thioglycolate tubes were incubated at $38^{\circ} \mathrm{C}$ for 24 hours. Blood agar media plates were streaked with sterile cotton-tipped applicators that had been immersed in the incubated brothspecimen mixture. The plates were placed in both aerobic and anaerobic environments at $38^{\circ} \mathrm{C}$ for an additional 24 hours.

The plates were evaluated for the presence of bacterial growth. Any growth in the swabbed area of the plate was considered positive. Statistical analysis was performed on the Michigan Terminal System using MIDAS (Statistical Research Laboratory, University of Michigan, Ann Arbor, MI). $\chi^{2}$ and logistical regression analysis were used as appropriate. A $P$ value of less than .05 was considered significant.

Animal welfare policies and standards of the American Associa tion for the Accreditation of Laboratory Animal Care were followed in conjunction with animal experimentation.

\section{RESULTS}

Figure 1 shows the linear correlation between weight and age. Bacterial growth of large and small bowel specimens increased significantly with both age and weight. Using regression analysis, age was found to have a slightly more significant effect than weight on the number of positive plates.

The percentage of plates with positive growth for each group and tissue specimen is shown in Table 1. Total growth, either aerobic or anaerobic, is listed in the first column. Positive growth on aerobic or anaerobic plates is shown in the second and third columns. There was no significant difference between aerobic and anaerobic growth in any category.

Figure 2 shows the percentage of positive growth (either aerobic or anaerobic) for each age group and tissue specimen. In group I, there was no bacterial growth from any LB or SB specimens. This was significantly different from the growth of RS or MS

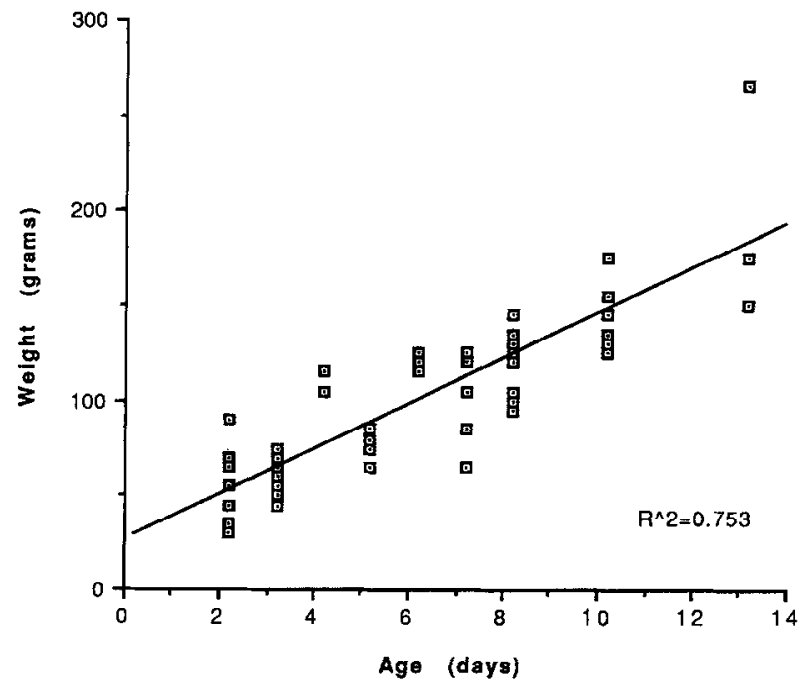

Fig 1. Linear correlation between weight and age.
Table 1. Bacterial Growth of Rectal Swabs, Mouth Swabs, Small Bowel, and Large Bowel

\begin{tabular}{|c|c|c|c|c|c|}
\hline Group & $n$ & Specimen & $\begin{array}{l}\% \text { Total } \\
\text { Growth }\end{array}$ & $\begin{array}{c}\% \text { Growth } \\
\text { of Aerobic } \\
\text { Plates }\end{array}$ & $\begin{array}{c}\% \text { Growth } \\
\text { of Anaerobic } \\
\text { Plates }\end{array}$ \\
\hline \multirow[t]{4}{*}{1} & 9 & RS & 89 & 89 & 89 \\
\hline & & MS & 100 & 100 & 100 \\
\hline & & SB & 0 & 0 & 0 \\
\hline & & LB & 0 & 0 & 0 \\
\hline \multirow[t]{4}{*}{ II } & 24 & RS & 100 & 100 & 100 \\
\hline & & MS & 100 & 100 & 100 \\
\hline & & SB & 25 & 21 & 17 \\
\hline & & LB & 62.5 & 50 & 62.5 \\
\hline \multirow[t]{4}{*}{ ill } & 27 & RS & 100 & 100 & 100 \\
\hline & & MS & 100 & 100 & 100 \\
\hline & & SB & 37 & 33 & 33 \\
\hline & & LB & 93 & 63 & 93 \\
\hline \multirow[t]{4}{*}{ IV } & 14 & RS & 100 & 100 & 100 \\
\hline & & MS & 100 & 100 & 100 \\
\hline & & SB & 64 & 50 & 64 \\
\hline & & LB & 100 & 100 & 100 \\
\hline
\end{tabular}

specimens, in which nearly all plates were positive ( $89 \%$ and $100 \%$, respectivcly).

Group II and III SB specimens demonstrated 25\% and $37 \%$ positive growth, respectively. The SB growth in these two groups was significantly lower than the MS or RS growth in either group (100\% for each category). The LB growth in groups II and III (62\% and $93 \%$, respectively) was lower than RS or MS growth ( $100 \%$ for each category); however, this was not significantly different.

Group IV LB, MS, and RS specimens all had bacterial growth. Sixty-four percent of SB specimens from this group also demonstrated growth. Statistical analysis of growth among different specimens from this group showed no significant differences.

\section{DISCUSSION}

Despite the fact that one of the most common causes of neonatal death is bacterial sepsis, ${ }^{7}$ little is known about the relationship that has developed

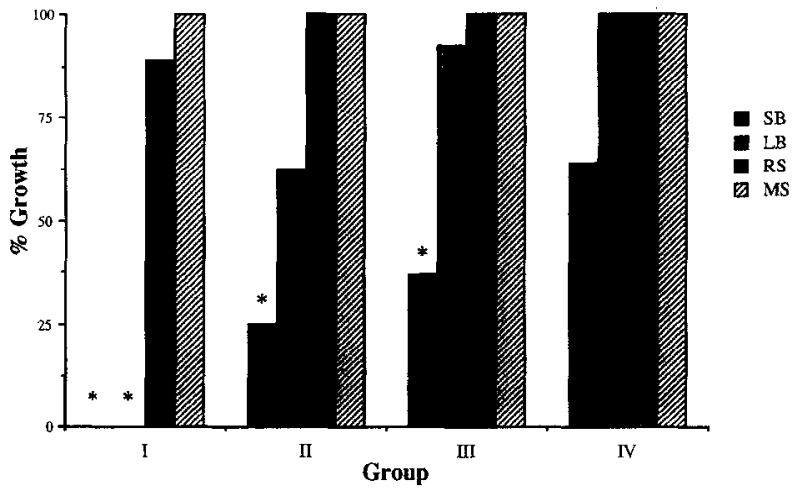

Fig 2. Percentage of growth (aerobic or anaerobic) for each group and tissue specimen. ${ }^{*} P<.05$. 
between humans and the $10^{14}$ microbes that inhabit their alimentary tracts. ${ }^{8}$ Although these bacteria may provide some benefit to humans, the intestinal flora are probably major contributors to the development of various diseases. The intestinal colonization of newborns is an essential component in the development of necrotizing enterocolitis; it also allows the process of bacterial translocation (the extraintestinal spread of intestinal bacteria) to occur, which may lead to sepsis, multiple-system organ failure, and eventually death. ${ }^{10}$

Most studies of intestinal microflora have been performed on fecal specimens or RS. These studies have defined the microbial growth patterns of the feces and/or rectum, but they do not evaluate the growth of bacteria in the proximal colon or terminal ileum. These areas are important because necrotizing enterocolitis tends to occur in these parts of the intestine, and bacterial translocation is believed to proceed across the terminal ileum and/or cecum. ${ }^{11}$ Moore et al performed studies on adult animals and humans to determine whether fecal flora was representative of flora activity throughout the colon. ${ }^{12}$ They found that the composition of the intestinal flora remained relatively constant from the ascending colon to the rectum in adult humans at risk for cancer. They concluded that in this group of adults, bacteria in the feces do reflect the flora of the colon. These studies have not been repeated in neonates.

Although the neonate is sterile until the time of birth,,$^{13}$ multiple studies have shown that colonization of the neonatal rectum begins within hours after birth. $3,7,14$ However, no previous study has evaluated the colonization of more proximal arcas of the bowel in the neonate. The results of the current study suggest that RS and/or MS flora are not representative of the flora of actual bowel specimens, and that RS and MS demonstrate bacterial growth several days earlier than the SB or LB specimens.

The reason for the delay in actual bowel specimen growth as opposed to swab growth was not evaluated in this study; however, the following are possible explanations. Perhaps bacteria enter the gastrointestinal tract through the mouth or the colon at the time of birth and then spread to the mid section of the intestine. This spread of bacterial colonization may take from several days to weeks. Our results suggest that, in rabbits, the bacteria spread to the proximal colon via the rectum during the first week of life. Spread of bacteria to the proximal colon from the rectum in human infants may take longer because of the increased length of the human colon and rectum. The SB has an even greater delay in colonization (about 2 weeks) and may never have $100 \%$ colonization. The delay in small intestinal colonization may be explained by a longer distance from the rectum to the SB, requiring more time for proximal spread. The bactericidal effect of gastric acid and/or upper intestinal motility may also explain this delay.

Our results also suggest a mechanism by which very young neonates protect themselves against bacterial translocation and the development of diseases such as neonatal sepsis and necrotizing enterocolitis. This protection is the absence of bacterial translocation in neonatal rabbits under 4 days of age, which was noted in preliminary studics in our laboratory. This absence results from the absent colonization of the small intestine and colon in very young rabbits (under 4 days of age). This correlates with the clinical observation that the onset of necrotizing enterocolitis in human infants is delayed until 10 to 15 days of age. ${ }^{15}$ The absence of bacteria in significant areas of the intestine for the first few days to weeks of life may result in a protection of the infant against the spread of bacterial infection from the intestinal tract to other sites of the body.

If one accepts the theory that mucosal immaturity is a major contributor to the high incidence of bacterial translocation in the newborn, then it is conceivable that there is a "danger period" after this early protection period. The "danger period" would begin several days to weeks after birth, when bacterial colonization has spread to the terminal ileum or proximal colon, and extend to that time after birth when the neonatal gut has matured. This theory could also explain the increased incidence of sepsis and necrotizing enterocolitis in premature infants. ${ }^{15,16}$ Because the premature infant presumably requires a longer period after birth until the intestinal mucosal barrier matures, the danger period and chance of developing sepsis would be present for a longer period after birth (Fig 3).

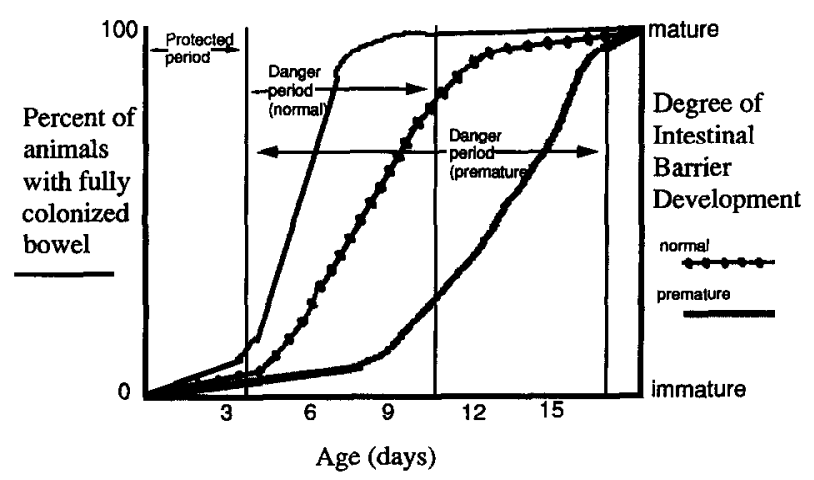

Fig 3. Proposed time line for risk of bacterial translocation in the neonate, based on maturation of intestinal barrier versus bacterial colonization. 
Future studies evaluating the effect of antibiotics, sterile environment, and/or the presence of specific types of bacteria are needed to more clearly understand neonatal intestinal colonization. This understanding will lead to the development of rational therapy for the prevention and treatment of neonatal sepsis.

\section{CONCLUSION}

We have shown that, in neonatal rabbits, the percentage of bacterial growth from actual small and large bowel specimens is significantly lower than that from rectal or mouth swabs. Our results suggest that the generally held belief that neonates experience colonization within 24 to 48 hours after birth is not correct. Instead, bacterial colonization of the proximal LB or terminal ileum, areas that are important in the pathogenesis of neonatal sepsis, may be delayed for several days to weeks after birth. The delay in bacterial growth in these areas of the intestine may provide protection for very young neonates against sepsis, multiple-system organ failure, and death. Further studies are needed to determine rational therapy for the prevention and treatment of neonatal sepsis.

\section{REFERENCES}

1. Van Camp JM, Tomasclli V, Drongowski R, ct al: Bacterial translocation in the neonate: The effect of age on the frequency of translocation. Pediatr Surg Int (in press)

2. Adlerberth I, Carlsson B, DeMan P, et al: Intestinal colonization with enterobacteriaceae in Pakistani and Swedish hospitaldelivered infants. Acta Paediatr Scand 80:602-610, 1991

3. Goldmann DA: Bacterial colonization and infection in the neonate. Am J Med 70:417-422, 1981

4. Smith HW, Crabb WE: The faecal bacterial flora of animals and man: Its development in the young. $J$ Pathol Bacteriol 82:53-66, 1961

5. Mata LJ, Urrutia JJ: Intestinal colonization of breast-fed children in a rural area of low socioeconomic level. Ann N Y Acad Sci 176:93-109, 1971

6. Bell MJ, Rudinsky M, Brotherton T, et al: Gastrointestinal microecology in the critically ill neonate. J Pediatr Surg 19:745-751, 1984

7. Hanson LA, Ashraf R, Cruz JR, et al: Immunity related to exposition and bacterial colonization of the infant. Acta Paediatr Scand 365:38-45, 1990

8. Luckey TD: Introduction to intestinal microecology. Am J Clin Nutr 25:1292-1294, 1972

9. Kosloske AM: A unifying hypothesis for pathogenesis and prevention of necrotizing enterncolitis. I Pediatr 117:S68-S74, 1990 (suppl)
10. Dietch EA: The role of intestinal barrier failure and bacterial translocation in the development of systemic infection and multiple organ failure. Arch Surg 125:403-404, 1990

11. Lawrence G, Bates J, Gaul A: Pathogenesis of neonatal necrotizing enterocolitis. Lancet 16:137-139, 1982

12. Moore WEC, Cato EP, Holdeman LV: Some current concepts in intestinal bacteriology. Am J Clin Nutr 31:S33-S42, 1978 (suppl)

13. Perman JA: Gastrointestinal flora: Developmental aspects and effects on nutrients, in Lebenthal $\mathrm{E}$ (ed): Human Gastrointestinal Development. New York, NY, Raven, 1989, pp 777-786

14. Lodinova-Zadnikova $\mathbf{R}$, Tlaskalova $\mathrm{H}$, Bartakova $\mathrm{Z}$ : The antibody response in infants after colonization of the intestine with $E$ Coli 083. Artificial colonization used as a prevention against nosocomial infections, in Melecky $J$ et al (eds): Immunology of Milk and the Neonate. New York, NY, Plenum, 1991, pp 329-335

15. Grosfeld JL, Cheu H, Schlatter M, et al: Changing trends in necrotizing enterocolitis. Experience with 302 cases in two decades. Ann Surg 214:300-307, 1991

16. Kosloske AM: Sepsis and infection in the neonate, in Fonkalsrud E, Krummel $\mathbf{T}$ (eds): Infections and Immunologic Disorders in Pediatric Surgery. Philadelphia, PA, Saunders, 1993, pp 131-136 